\title{
Tuberculosis complicating imatinib treatment for chronic myeloid leukaemia
}

\author{
J.M.A. Daniels*, A. Vonk-Noordegraaf*, J.J.W.M. Janssen\#, P.E. Postmus* and \\ R. van Altena
}

ABSTRACT: Although imatinib is not considered a predisposing factor for tuberculosis (TB), the present case report describes three patients in whom imatinib treatment for chronic myeloid leukaemia was complicated by TB. This raises the question of whether imatinib increases susceptibility to TB.

There are several reports suggesting that imatinib might impair the immune system, leading to a variety of infections, including varicella zoster and hepatitis B. Control of TB in healthy individuals is achieved through acquired immunity, in which antigen-specific T-cells and macrophages arrest growth of Mycobacterium tuberculosis bacilli and maintain control over persistent bacilli. In the chronic stage of the infection, CD8+ T-cells assist macrophages in controlling intracellular mycobacteria. The T-cell receptor orchestrates this process.

The fact that tyrosine kinases play an important role in T-cell receptor signal transduction and that imatinib has been shown to affect T-cell receptor signal transduction, presents a mechanism by which imatinib might impair control of Mycobacterium tuberculosis; thereby leaving the host susceptible to reactivation of tuberculosis.

KEYWORDS: Chronic myeloid leukaemia, imatinib, immunity, infection, T-cell receptor, tuberculosis

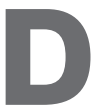
espite the introduction of effective antibiotics against Mycobacterium tuberculosis, tuberculosis (TB) is certainly not a disease of the past, with $\sim 10$ million new cases recorded each year. In the Netherlands, TB is most common in high-risk groups, these include: foreign-born patients from countries with high TB prevalence; HIV-infected persons; the elderly; those in close contact with suspected TB patients; medically underserved low-income populations; alcoholics and intravenous drug users; and residents of institutions, such as long-term care facilities. Several malignancies, especially haematological ones, might also lead to increased rates of TB [1]. However, there is little or no evidence that chronic myeloid leukaemia (CML) predisposes people to TB $[1,2]$.

Several drugs induce susceptibility to TB, such as tumour necrosis factor- $\alpha$ antagonists and possibly corticosteroids. Imatinib is a 2-phenylaminopyrimidine compound that selectively inhibits proliferation of CML cells by blocking the tyrosine kinase activity of the Bcr-Abl protein. Since the IRIS study (International Randomized Study of Interferon versus STI571) [3, 4] demonstrated efficacy superior to interferon plus cytarabine, imatinib is now widely used as a first-line single agent for newly diagnosed chronic-phase CML. Although imatinib is not considered a predisposing factor to $\mathrm{TB}$, the present case report describes three patients in whom imatinib treatment for CML was complicated by TB. A mechanism by which imatinib may lead to increased susceptibility to TB is proposed.

\section{CASE 1}

A 38-yr-old Caucasian male with a Dutch background was referred after several months of fatigue, fever, productive cough and night sweats. $\mathrm{He}$ had been diagnosed with Bcr-Abl positive CML 4 yrs earlier. This was treated with hydroxycarbamide (1 g twice daily) for several weeks, followed by imatinib ( $800 \mathrm{mg}$ daily) and two courses of cytarabine $\left(200 \mathrm{mg} \cdot \mathrm{m}^{-2}\right)$, which led to a complete cytogenetic and a major haematological response. Imatinib was continued as maintenance therapy. Physical examination demonstrated no abnormalities besides a fever. Laboratory workup showed a normal leukocyte count of $5.0 \times 10^{9} \mathrm{~L}^{-1}$ (normal: $4.0-10.0 \times 10^{9} \mathrm{~L}^{-1}$ ) with a normal differential count and haemoglobin measurement of $7.1 \mathrm{mmol} \cdot \mathrm{L}^{-1}$

\section{AFFILIATIONS}

Depts of *Pulmonary Diseases, and \#Haematology, VU University Medical Centre, Amsterdam, and "Dept of Tuberculosis, University Medical Centre, Groningen, The Netherlands.

CORRESPONDENCE

J.M.A. Daniels

Dept of Pulmonary Diseases Medisch Centrum Alkmaar

Wilhelminalaan 12

Alkmaar

Noord-Holland

1815 JD

The Netherlands

Fax: 31725482167

E-mail: j.m.a.daniels@mca.nl

Received:

February 182008

Accepted after revision:

May 252008

STATEMENT OF INTEREST

None declared.

European Respiratory Journal

Print ISSN 0903-1936

Online ISSN 1399-3003 
(normal: $8.7-11.2 \mathrm{mmol} \cdot \mathrm{L}^{-1}$ ). C-reactive protein (CRP) and erythrocyte sedimentation rate (ESR) were not performed. A chest radiograph revealed a large cavitating lesion in the apical segment of the right upper lobe. The direct smear of spontaneously expectorated sputum was positive for acid-fast bacilli, and TB was confirmed by PCR and Löwenstein culture. Treatment with 2 months of pyrazinamid and ethambutol and 6 months of isoniazid and rifampicin was initiated. Within the first 2 months of treatment all symptoms completely resolved and the sputum smear became negative. Treatment with imatinib was continued. The patient had travelled abroad in a group 15 yrs earlier. A fellow traveller with a persistent cough was diagnosed at a later date with TB. At that time, screening for TB by skin test was negative in three out of six persons, including the current patient.

\section{CASE 2}

A 26-yr-old male African refugee was referred with a 3 month history of backache. He had been diagnosed with Bcr-Abl positive CML 2 yrs previously and had been treated with hydroxycarbamide. After 2 yrs the chronic-phase CML progressed to accelerated phase and hydroxycarbamide was replaced by imatinib (400 $\mathrm{mg}$ daily), which the patient has been taking ever since. The backache was centred caudally of the fifth thoracic vertebra, radiating to the left posterior thoracic wall and axilla. Physical examination revealed no abnormalities and no signs of spinal cord involvement. Laboratory examination showed an elevated leukocyte count $12.6 \times 10^{9} \mathrm{~L}^{-1}$ (normal: 4.0-10.0 $\times 10^{9} \mathrm{~L}^{-1}$ ) and low haemoglobin $7.3 \mathrm{mmol} \cdot \mathrm{L}^{-1}$ (normal: $8.7-11.2 \mathrm{mmol} \cdot \mathrm{L}^{-1}$ ). CRP was $21 \mathrm{mg} \cdot \mathrm{L}^{-1}$ (normal: $1-10 \mathrm{mg} \cdot \mathrm{L}^{-1}$ ) and ESR was $80 \mathrm{~mm}$ (normal: $<10 \mathrm{~mm}$ ). Serum glutamic oxaloacetic transaminase was $268 \mathrm{U} \cdot \mathrm{L}^{-1}$ (normal: $15-35 \mathrm{U} \cdot \mathrm{L}^{-1}$ ) and serum glutamic pyruvic transaminase was $391 \mathrm{U} \cdot \mathrm{L}^{-1}$ (normal: $22-30 \mathrm{U} \cdot \mathrm{L}^{-1}$ ). The Mantoux test was not performed and HIV serology was negative. A chest radiograph was normal besides fusion of lumbar vertebrae L1L2. Spinal magnetic resonance imaging with contrast enhancement showed a paravertebral mass left of T8. As outlined previously [5], this lesion was initially misdiagnosed as a chloroma and treated with 16 Gy of radiotherapy. However, the lesion enlarged after 2 months. Histological examination of a surgical biopsy specimen showed caseous granulomatous necrotic tissue, suspect for TB. Acid-fast bacilli stain and PCR were both negative but the TB culture was positive. Treatment was started with 2 months of pyrazinamid and ethambutol and 6 months of isoniazid and rifampicin. All symptoms resolved and there was no relapse.

\section{CASE 3}

A 19-yr-old male refugee from Africa with a history of posttraumatic stress disorder and chronic unclassified psychosis presented with fever, cough and weight loss. A year earlier he had been diagnosed with Bcr-Abl positive CML and since then had been treated with imatinib (400 mg daily). Haematological response was achieved but varied with compliance to therapy. Physical examination revealed no abnormalities other than cachexia. Laboratory examination showed normal leukocytes and low haemoglobin of $6.5 \mathrm{mmol} \cdot \mathrm{L}^{-1}$ (normal: $8.7-11.2 \mathrm{mmol} \cdot \mathrm{L}^{-1}$ ), while CRP was $83 \mathrm{mg} \cdot \mathrm{L}^{-1}$ (normal: $1-10 \mathrm{mg} \cdot \mathrm{L}^{-1}$ ). A chest radiograph revealed a large cavitating lesion in the apical segment of the left lower lobe. No acid-fast bacilli were found in the sputum and TB cultures remained negative. However, the quality of the samples was inadequate due to poor cooperation of the patient. Empirical treatment was started with 2 months of pyrazinamid and ethambutol and 6 months of isoniazid and rifampicin while imatinib was continued. Because of poor initial compliance the patient was admitted to a TB hospital for almost 5 months. During this period he recovered well and gained $13 \mathrm{~kg}$. HIV serology was negative.

\section{DISCUSSION}

CML is a myeloproliferative disorder that arises in a hematopoietic stem cell or an early progenitor cell and, if left untreated, leads to fatal blast crisis closely resembling acute myeloid or lymphoid leukaemia. Although an association between lymphoid malignancies and TB has been described, this is not the case for CML. In a retrospective review by SILVA et al. [2], 917 cases with haematological malignancies in Brazil were reviewed. TB was diagnosed in 24 cases and most frequently in nonHodgkin lymphoma (NHL; 11 out of 299 cases) and chronic lymphocytic lymphoma (five out of 67 cases), but only the latter showed an increased odds ratio of $3.24,95 \%$ confidence interval $1.17-8.96(p=0.03)$. Out of $45 \mathrm{CML}$ cases only one had developed TB. KAMBOJ and SEPKOWITZ [1] reviewed all confirmed TB cases at the Memorial Sloan-Kettering Cancer Centre (New York, NY, USA) from 1980 to 2004 . In total, 290 cases were identified and the calculated incidence was 50 per 100,000 persons. The incidence of TB was highest among patients with haematological malignancies, especially in non-natives. TB was diagnosed most frequently in those with NHL, Hodgkin lymphoma and, as expected, among severely immunosuppressed allogeneic haematopoietic stem cell transplant recipients.

Although the diagnosis of TB was not bacteriologically confirmed in case 3, the clinical picture and complete response during treatment make the diagnosis highly likely. The fact that all three patients were treated with imatinib raises the question of whether this drug increases susceptibility to TB. To date, only one case has been reported where neutropenia and TB complicated treatment with imatinib for gastrointestinal stromal tumour [6]. However, there are several reports suggesting that imatinib might impair the immune system, leading to a variety of infections, including varicella zoster and hepatitis B [7-9]. In vitro studies show inhibition of the development of $\mathrm{CD} 34^{+}$progenitor cell-derived dendritic cells with a reduced capacity to induce a cytotoxic T-cell response [10] and a dose-dependent reduction of the T-cell population [11-13]. In vivo studies demonstrate reversible and dosedependent lymphopenia and hypogammaglobulinemia [14], and impaired CD8 T-cell responses [15, 16]. Interestingly, MUMPRECHT et al. [16] observed an intact control of primary viral infections in spite of the impaired cytotoxic T-cell response. Therefore, imatinib might not affect control of primary infections but rather control of chronic infections. As all three patients described herein were very likely exposed to TB earlier, reactivation of TB was probably the case. Furthermore, the infections that have been described during imatinib treatment so far are also typically chronic infections with a tendency to reactivate [7-9]. Control of TB in healthy individuals is achieved through acquired immunity, in which antigen-specific T-cells and macrophages arrest growth of Mycobacterium tuberculosis and maintain control over persistent 
bacilli [17]. In the chronic stage of the infection, CD8+ T-cells assist macrophages in controlling intracellular mycobacteria. Activation of T-cells in response to antigens is regulated by the T-cell receptor. The fact that tyrosine kinases play an important role in T-cell receptor signal transduction and that imatinib has been shown to affect $\mathrm{T}$-cell receptor signal transduction [11] presents a mechanism by which imatinib might impair control of Mycobacterium tuberculosis, thereby leaving the host susceptible to reactivation of TB.

In conclusion, imatinib clearly affects the immune system and $\mathrm{T}$-cell response in particular. This might induce reactivation of chronic viral infections or tuberculosis. Further research is necessary to assess whether there is an association between the effects of imatinib on the immune system and reactivation of tuberculosis. If this is the case, the risk of tuberculosis infection should be assessed prior to imatinib therapy.

\section{REFERENCES}

1 Kamboj M, Sepkowitz KA. The risk of tuberculosis in patients with cancer. Clin Infect Dis 2006; 42: 1592-1595.

2 Silva FA, Matos JO, de Q Mello FC, Nucci M. Risk factors for and attributable mortality from tuberculosis in patients with hematologic malignances. Haematologica 2005; 90: 1110-1115.

3 Druker BJ, Guilhot F, O'Brien SG, et al. Five-year follow-up of patients receiving imatinib for chronic myeloid leukemia. N Engl J Med 2006; 355: 2408-2417.

4 O'Brien SG, Guilhot F, Larson RA, et al. Imatinib compared with interferon and low-dose cytarabine for newly diagnosed chronic-phase chronic myeloid leukemia. $N$ Engl J Med 2003; 348: 994-1004.

5 Jutte PC, van Altena R, Pras E, Thijn CJ. Causes of misdiagnosis and mistreatment of spinal TB with radiotherapy in non-endemic areas: a pitfall in diagnosis and treatment. Spine 2005; 30: E300-E304.

6 Takashima M, Igaki N, Matsuda $\mathrm{T}$, et al. Malignant gastrointestinal stromal tumor of the small intestine complicated with pulmonary tuberculosis during treatment with imatinib mesylate. Intern Med 2005; 44: 114-119.
7 Ikeda K, Shiga Y, Takahashi A, et al. Fatal hepatitis B virus reactivation in a chronic myeloid leukemia patient during imatinib mesylate treatment. Leuk Lymphoma 2006; 47: 155-157.

8 Mattiuzzi GN, Cortes JE, Talpaz M, et al. Development of Varicella-Zoster virus infection in patients with chronic myelogenous leukemia treated with imatinib mesylate. Clin Cancer Res 2003; 9: 976-980.

9 Durosinmi MA, Ogbe PO, Salawu L, Oyekunle AA. Herpes zoster complicating imatinib mesylate for gastrointestinal stromal tumour. Intern Med 2005; 44: 114-119.

10 Appel S, Boehmler AM, Grünebach F, et al. Imatinib mesylate affects the development and function of dendritic cells generated from CD34+ peripheral blood progenitor cells. Blood 2004; 103: 538-544.

11 Seggewiss R, Loré K, Greiner E, et al. Imatinib inhibits Tcell receptor-mediated T-cell proliferation and activation in a dose-dependent manner. Blood 2005; 105: 2473-2479.

12 Cwynarski K, Laylor R, Macchiarulo E, et al. Imatinib inhibits the activation and proliferation of normal $\mathrm{T}$ lymphocytes in vitro. Leukemia 2004; 18: 1332-1339.

13 Dietz AB, Souan L, Knutson GJ, Bulur PA, Litzow MR, Vuk-Pavlovic S. Imatinib mesylate inhibits T-cell proliferation in vitro and delayed-type hypersensitivity in vivo. Blood 2004; 104: 1094-1099.

14 Steegmann JL, Moreno G, Aláez C, et al. Chronic myeloid leukemia patients resistant to or intolerant of interferon alpha and subsequently treated with imatinib show reduced immunoglobulin levels and hypogammaglobulinemia. Haematologica 2003; 88: 762-768.

15 Sinai P, Berg RE, Haynie JM, Egorin MJ, Ilaria RL Jr, Forman J. Imatinib mesylate inhibits antigen-specific memory CD8 T cell responses in vivo. J Immunol 2007; 178: 2028-2037.

16 Mumprecht S, Matter M, Pavelic V, Ochsenbein AF. Imatinib mesylate selectively impairs expansion of memory cytotoxic $\mathrm{T}$ cells without affecting the control of primary viral infections. Blood 2006; 108: 3406-3413.

17 Boom WH, Canaday DH, Scott AF, Gehring AJ, Rojas RE, Torres M. Human immunity to M.tuberculosis: T cell subsets and antigen processing. Tuberculosis 2003; 83: 98-106. 